\title{
Marketing Strategy for Soybean Products: Familiarity Breeds Content
}

\author{
Kwaku Ahenkora (Corresponding author) \\ Christian Service University College \\ PO Box 3310, Kumasi, Ghana
}

Tel: 233-5-4556-9239 E-mail: k.ahenkora@yahoo.co.uk

\author{
Yarhands Dissou Arthur \\ Christian Service University College \\ PO Box 3310, Kumasi, Ghana \\ Tel: 233-3-2202-8781 \\ Stephen Banahene \\ Christian Service University College \\ PO Box 3310, Kumasi, Ghana
}

Tel: 233-3-22028781

$\begin{array}{ll}\text { Received: April 28, } 2011 & \text { Accepted: March 2, } 2012 \quad \text { Published: June 1, } 2012 \\ \text { doi:10.5539/ijms.v4n3p186 } & \text { URL: http://dx.doi.org/10.5539/ijms.v4n3p186 }\end{array}$

\begin{abstract}
The study used newly introduced soymilk product to explore the effects of familiarity, exposure and product information on product usage. The results showed that familiarity affected usage, exposure positively influenced usage decisions but product information did not have effect on acceptability. The study suggests that the experience derived from product trial may have a greater effect on intention to purchase than mere information. Promotional "exposure" may be used by marketers to nudge customers towards familiarity.
\end{abstract}

Keywords: Familiarity, Exposure, Marketing, Consumer expectancies, Product acceptance

\section{Introduction}

Soybean improvement programmes in scientific and industrial research have led to the introduction of varieties and promotion of the crop in cultures which are not familiar with them. Culture influences consumer behaviour and the application of emerging technologies to food production is very much dependent on the social context in which the technology is embedded (Frewer, 1998; Ilyas, Hussain \& Usman, 2011). This implies the need for investigating consumer concerns and expectations about food and emerging technologies (Cardello, 2003; Cardello, Schutz, \& Lesher, 2007). Consumers choose products on the basis of the information on some characteristics, which work as cues that say something about the product and they can be intrinsic and extrinsic (Berneus, Olaizola, \& Corcoran, 2003). Intrinsic cues relate to the physical aspects of the product such as colour, aroma, and flavour, whereas extrinsic cues are related to the product but are not physically part of it and include brand, origin, packaging, price, store, advertisement, production information, technology information (Finco, Deliza, Rosenthal \& Silva, 2010).

Consumer choice is a complex phenomenon as it is interrelated with ecological, social, political, ethical, economic and technological problems and continues to raise the fundamental question: what are the sources of consumer dissatisfaction? Although the primary factors controlling purchase and consumption are availability, cost and preference, additional factors that increase self-exposure include advertising, product name, packaging, nutritional information, usage information, and presentation of product in an appealing form or recipe (Cardello, Maller, Masor, Dubose \& Edelman, 1985). Food package and food label play important roles in consumer food choice as well as in product intention to purchase (Brandt, Spease, June \& Brown, 2003). In predicting the effects of product evaluation on customer satisfaction and the disparity between expectation and actual or 
objective product performance, four psychological theories are usually considered, namely, cognitive dissonance (assimilation), contrast, generalised negativity, and assimilation-contrast. Dissonance or assimilation theory posits that any discrepancy between expectations and product performance will be minimised or assimilated by the consumer adjusting his perception of the product to be inconsistent (less dissonant) with his expectations (Anderson, 1973). Much has been written about the importance of consumer expectations, particularly their impact on purchasing behaviour, their effects on consumer dissatisfaction, and the effects of product usage experience that confirms pre-trial expectations.

Modelling choices among alternative responses to dissatisfaction have engaged consumer behaviourists (Day, 1984). Cardello et al. (1985) proposed the theoretical framework, based on the theory of cognitive dissonance, that the hedonic response to food is a function of the degree to which expectancies about the food are matched by subsequent experience with it. Subsequent studies on consumer expectancies and acceptance of novel food confirmed this theoretical framework as an analytic tool for predicting consumer responses to food (Ahenkora \& Sobotie, 2005). These studies on novel foods identified several factors such as preparation variables, product name, brand labels and packaging, availability of product information and degree of familiarity of the user with the product. Consumer satisfaction, then, might be measured by the degree of congruence between expectations and perceived product performance.

This work, therefore, aimed to investigate the effects of exposure and familiarity on soymilk usage intentions. Soymilk usage intention was investigated considering that for consumers who avoid soymilk due to lack of familiarity, exposure will confirm or disconfirm their expectancies.

\section{Method}

Experiments were conducted with 56 volunteer untrained panellists (equal number of males and females) using methods previously described (Ahenkora \& Sobotie, 2005; Cardello et al., 1985). They were recruited from the staff of the Crops Research Institute and Ministry of Food and Agriculture. Panellists were given explanations about the exercise which aimed at promoting new milk product and what they were expected to do. Before the evaluation of the test samples, panellists were given a short usage survey of soymilk to complete. The survey asked whether the panellist had used soymilk product within the past 6 months. The survey indicated that $43 \%$ of the panellists were non-users while $57 \%$ were users. In assessing the effect of the availability of product information, two samples of the same soymilk products were given to panellists. One of the test samples was labelled and evaluated as "soymilk" while the other was not labelled. Panellists were given random samples to judge and were asked to evaluate milk samples for overall acceptance. A nine-point, labelled hedonic scale was used to make all judgements and the results of the experiments were analysed by Analysis of Variance Techniques (Larmond, 1977). After the taste sessions, panellists were given another survey forms which asked whether they would buy and use soymilk. The effects of exposure, prior use or non-use on the acceptance score were evaluated.

\section{Results and Discussion}

\subsection{Familiarity with the Product}

Table 1 shows the effects of prior-use and non-use on the overall acceptability of soymilk. There was a significant difference $(\mathrm{P}<0.05)$ in acceptability. Panellists who were familiar with soymilk, significantly $(\mathrm{P}<0.05)$ preferred it to those who were not familiar with the product (Table 1).

\subsection{Availability of Product Information}

The result of availability of product information on acceptance of milk products is shown in Table 2. Although there were differences in the mean scores for soymilk presented to panellists and labelled, and soymilk not labelled, this was not significant.

\subsection{Exposure}

The percentage of users and non-users of soymilk before and after sensory evaluation are shown in Table 3 . After the experiments, a significant $(\mathrm{P}<0.05)$ number of panellists, that is, $32 \%$ more people, who were previously not familiar with soymilk were willing to use it.

The above results suggest that panellists' response to soymilk is related to familiarity or non-familiarity of the user with the product. Soymilk was more acceptable to panellists who were familiar with soymilk (prior-users) than non-users. Exposure to soymilk also influenced usage intentions. It corroborates views, which might be intuitively expected, that product usage experience appears to have a strong impact on belief-expectancy elements of cognitive structure (Olson \& Dover, 1976). The effects on individuals of confirmed expectancies is 
critical for designing promotional mixes and, for soybeans, there may be policy implications for quality control, price, promotion and other elements of the marketing mix depending upon whether consumer expectations are too high, product performance too low or promotional messages misplaced, i.e., aimed at generating an inappropriate level of expectations. While culture's impact on consumer behaviour may be controlled by marketing communication (Luna \& Gupta, 2001), in the current study, product information was of little importance, suggesting that the experience derived from product trial may have a greater effect on acquisition than mere information. It suggests that packaging attributes and marketing strategies should be developed following a consumer orientation to provide good results on the acceptance of novel products (Finco, Deliza, Rosenthal, \& Silva, 2010) Based on the literature dealing with the relationships between beliefs, attitudes, behavioural intention, and actual behaviour, consumer expectations, conceptualised as beliefs, may be theoretically linked with subsequent overt behaviours such as purchase (Olson \& Dover, 1976). Post-trial cognitive changes following a disconfirming experience may be caused by dissonance reduction. The effects of exposure in putting non-users on familiar track and intention to purchase suggest the importance of 'promotional exposure' as nudging tool by marketers.

\section{Conclusion}

This study suggests that acceptability is influenced by the degree of familiarity with soymilk and high satisfaction derived from exposure influenced consumer intention to purchase. While the study was limited by generalisation of familiarity, it nonetheless opens up avenues for further research on consumer expectancies, degree of familiarity and product acceptance and suggests the nudging effects of promotional "exposure" as a useful marketing strategy.

\section{References}

Ahenkora, K., \& Sobotie, S. (2005). Consumer expectancies and acceptance of novel foods. Ghana Jnl Agric Sci. NARS edn No. 1, 169-173. http://dx.doi.org/10.1016/S0950-3293(02)00085-X

Anderson, R. E. (1973). Consumer dissatisfaction: The effect of disconfirmed expectancy on perceived product performance. Journal of Marketing Research, 10(1), 38-44.

Bernues, A., Olaizola, A., \& Corcoran, K. (2003). Extrinsic attributes of red meat as indicators of quality in Europe: An application for market segmentation. Food Quality and Preference, 14, 265-276.

Brandt, M. B., Spease, C. J., June, G., \& Brown, A. M. (2003). Prevalance of food safety, quality, and other consumer statements on labels of processed, packaged foods. Food Protection Trends, 23, 870-881.

Cardello, A. V. (2003). Consumer concerns and expectations about novel food processing technologies: Effects on product liking. Appetite, 40, 217-233. http://dx.doi.org/10.1016/S0195-6663(03)00008-4

Cardello, A. V., Maller, O., Masor, H. B., Dubose, C., \& Edelman, B. (1985). Role of consumer expectancies in the acceptance of novel foods. Journal of Food Science, 50, 1707-1714. http://dx.doi.org/10.1111/j.1365-2621.1985.tb10571.x

Cardello, A. V., Schutz, H. G., \& Lesher, L. L. (2007). Consumer perception of foods processed by innovative \& emerging technologies: A conjoint analytic study. Innovative Food Science \& Emerging Technologies, 8, 73-83. http://dx.doi.org/10.1016/j.ifset.2006.07.002

Day, L. R. (1984). Modeling choices among alternative responses to dissatisfaction. Advances in Consumer Research, 2, 496-199

Finco, F. D. B. A., Deliza, R., Rosenthal, A., \& Silva, C. H. O. (2010). The effect of extrinsic product attributes of pineapple juice on consumer intention to purchase. Journal of Food \& Agribusiness Marketing, 22, 125-142. http://dx.doi.org/10.1080/08974430903372963

Frewer, L. (1998). Consumer perceptions and novel food acceptance. Outlook on Agriculture, 27, 153-156.

Ilyas, S., Hussain, M. F., \& Usman, M. (2011). An integrative framework for consumer behaviour. Int. Journal of Business and Management, 6(4), 120-128.

Larmond, E. (1977). Laboratory methods for sensory evaluation of foods. Canada Department of Agriculture. Publication 1637. Ottawa.

Luna, D., \& Gupta, F. S. (2001). An integrative framework for cross-cultural consumer behaviour. International Marketing Review, 18(1), 45-69. http://dx.doi.org/10.1108/02651330110381998

Olson, J. C., \& Dover, P. (1976). Effects of expectation creation and disconfirmation on belief elements of cognitive structure. Advances in Consumer Research, 3, 168-175. 
Table 1. Effect of prior use or non-use on overall acceptance of soymilk

\begin{tabular}{|c|c|c|}
\hline \multirow{2}{*}{ Product } & \multicolumn{2}{|c|}{ Overall acceptance } \\
\cline { 2 - 3 } & Users & Nonusers \\
\hline Soymilk & $7.14 \mathrm{a}$ & $6.23 \mathrm{~b}$ \\
\hline
\end{tabular}

Note: a-b. Means with different letters are significantly different $(\mathrm{P}<0.05)$

Table 2. Effect of product information on overall acceptance of soymilk

\begin{tabular}{|c|c|}
\hline Product Information & Overall acceptance* \\
\hline Soymilk (labelled) & $7.45 \mathrm{a}$ \\
\hline Soymilk (not labelled) & $7.20 \mathrm{a}$ \\
\hline
\end{tabular}

Note: a Means with same letters do not differ significantly $(\mathrm{P}<0.05)$. *Mean score for 56 panellists

Table 3. Percentage of users and non-users of soymilk before and after sensory evaluation

\begin{tabular}{|c|c|c|c|c|}
\hline \multirow{2}{*}{ Product } & \multicolumn{2}{|c|}{ Before sensory evaluation } & \multicolumn{2}{c|}{ After sensory evaluation } \\
\cline { 2 - 5 } & Non-users & Users & Non-users & Users \\
\hline Soymilk & 43 & 57 & 11 & $89\left(+32.0^{* *}\right)$ \\
\hline
\end{tabular}

Note: ( ) Figures in parenthesis show percentage increase+, of users after experiment and values with asterisk** shows a significant t-test value at the $5 \%$ level. 